\title{
Five percent dextrose maximizes dose delivery of Yttrium-90 resin microspheres and reduces rates of premature stasis compared to sterile water
}

\author{
MARY ELLEN KORAN, SAMANTHA STEWART, JENNIFER C. BAKER, \\ ANDREW J. LIPNIK, FIL BANOVAC, REED A. OMARY and DANIEL B. BROWN \\ Department of Radiology and Radiologic Sciences, Vanderbilt University \\ School of Medicine, Nashville, TN 37232, USA
}

Received September 12, 2016; Accepted October 26, 2016

DOI: $10.3892 /$ br.2016.799

\begin{abstract}
Resin Yttrium-90 (Y90) microspheres have historically been infused using sterile water $\left(\mathrm{H}_{2} \mathrm{O}\right)$. In 2013, recommendations expanded to allow delivery with $5 \%$ dextrose in water $\left(\mathrm{D}_{5} \mathrm{~W}\right)$. In this retrospective study, we hypothesized that $\mathrm{D}_{5} \mathrm{~W}$ would improve $\mathrm{Y} 90$ delivery with a lower incidence of stasis. We reviewed 190 resin Y90 infusions using $\mathrm{H}_{2} \mathrm{O}(\mathrm{n}=137)$ or $\mathrm{D}_{5} \mathrm{~W}(\mathrm{n}=53)$. Y90 dosimetry was calculated using the body surface area method. Infusion was halted if intra-arterial stasis was fluoroscopically identified prior to clearing the vial. Differences between $\mathrm{H}_{2} \mathrm{O}$ and $\mathrm{D}_{5} \mathrm{~W}$ groups were calculated for activity prescription, percentage of cases reaching stasis, and percentage delivery of prescribed activity using $\mathrm{z}$ - and t-test comparisons, with $\alpha=0.05$. Thirty-one of $137 \mathrm{H}_{2} \mathrm{O}$ infusions developed stasis compared to 2 of 53 with $\mathrm{D}_{5} \mathrm{~W}(\mathrm{z}=3.07, \mathrm{p}=1.05 \mathrm{E}-03) . \mathrm{D}_{5} \mathrm{~W}$ also had a significantly higher prescribed activity than $\mathrm{H}_{2} \mathrm{O}$ [28.2 millicuries (mCi) vs. $20.4 \mathrm{mCi}$, respectively; $\mathrm{t}=5.0, \mathrm{p}=1.1 \mathrm{E}-6] . \mathrm{D}_{5} \mathrm{~W}$ had a higher delivery percentage of the prescribed dose compared to $\mathrm{H}_{2} \mathrm{O}$ (101.5 vs. $92.7 \%$, respectively; $\mathrm{t}=3.8, \mathrm{p}=1.92 \mathrm{E}-4)$. In conclusion, resin microsphere infusion utilizing $\mathrm{D}_{5} \mathrm{~W}$ has a significantly lower rate of stasis than $\mathrm{H}_{2} \mathrm{O}$ and results in more complete dose delivery. $\mathrm{D}_{5} \mathrm{~W}$ is preferable to $\mathrm{H}_{2} \mathrm{O}$ for resin microsphere infusion.
\end{abstract}

Correspondence to: Dr Daniel B. Brown, Department of Radiology and Radiologic Sciences, Vanderbilt University School of Medicine, 1161 Medical Center Drive, CCC-1118 Medical Center North, Nashville, TN 37232, USA

E-mail: daniel.b.brown@vanderbilt.edu

Abbreviations: Y90, Yttrium-90; Bq, Becquerel; $\mathrm{H}_{2} \mathrm{O}$, water; $\mathrm{D}_{5} \mathrm{~W}$, $5 \%$ dextrose in water; $\mathrm{BSA}$, body surface area; $\mathrm{V}_{\text {tumor }}$, volume tumor; $\mathrm{V}_{\text {liver }}$, volume liver

Key words: radioembolization, metastatic disease, liver, locoregional therapy, yttrium-90, palliative therapy

\section{Introduction}

Yttrium-90 (Y90) microspheres are used to treat patients with primary hepatic and liver-dominant metastatic cancer. The glass and resin Y90 products differ significantly in the density of radionuclide per bead. Glass microspheres have a higher density [2,500 Becquerel (Bq)/bead] of Y90 than resin (50 Bq/bead) (1). The higher Y90 concentration in glass beads allows the delivery of prescribed activity without feeding artery occlusion, a known issue with resin microspheres. From the time of government approval in 2002, the standard technique for infusion of resin microspheres used sterile water $\left(\mathrm{H}_{2} \mathrm{O}\right)$ alternating with small aliquots of contrast to evaluate for arterial stasis prior to delivery of the entire dose vial $(2,3)$. While clinical outcomes have resulted in excellent control of hepatic disease, a previous review using $\mathrm{H}_{2} \mathrm{O}$ to inject resin microspheres identified a $20 \%$ early stasis rate (4-6).

Delivering less than the prescribed Y90 activity has the potential to reduce treatment efficacy or result in earlier time to progression. Therefore, investigation of other injection methods for resin microspheres is required. In 2013, our group began to use $5 \%$ dextrose in water $\left(\mathrm{D}_{5} \mathrm{~W}\right)$ as an alternative to $\mathrm{H}_{2} \mathrm{O}(7)$.

The aim of the current study was to measure the incidence of premature stasis using $\mathrm{D}_{5} \mathrm{~W}$ in comparison to $\mathrm{H}_{2} \mathrm{O}$. We hypothesized that $\mathrm{D}_{5} \mathrm{~W}$ induces stasis less frequently than $\mathrm{H}_{2} \mathrm{O}$ in a clinical cohort of patients with primary or secondary hepatic malignancy.

\section{Materials and methods}

Clinical setting and patients. Our Institutional Review Board approved this retrospective study. All the procedures performed were in accordance with the ethical standards of the Vanderbilt University School of Medicine and with the 1964 Helsinki declaration and its later amendments or comparable ethical standards.

We retrospectively reviewed laboratory, radiology and nuclear pharmacy reports of all resin Y90 infusions performed between July, 2013 and July, 2014. Consecutive patients treated after September, 2013, were treated with 
Table I. Breakdown of infusion regimens and stasis events by tumor type.

\begin{tabular}{|c|c|c|c|c|c|c|c|c|}
\hline Variables & $\begin{array}{l}\mathrm{H}_{2} \mathrm{O} \\
\text { patient }\end{array}$ & $\begin{array}{l}\mathrm{H}_{2} \mathrm{O} \\
\text { infusions }\end{array}$ & $\begin{array}{l}\text { Stasis } \\
\text { events }\end{array}$ & $\begin{array}{l}\text { Stasis } \\
(\%)\end{array}$ & $\begin{array}{l}\mathrm{D}_{5} \mathrm{~W} \\
\text { patients }\end{array}$ & $\begin{array}{l}\mathrm{D}_{5} \mathrm{~W} \\
\text { infusions }\end{array}$ & $\begin{array}{l}\text { Stasis } \\
\text { events }\end{array}$ & $\begin{array}{l}\text { Stasis } \\
(\%)\end{array}$ \\
\hline Total & 78 & 137 & 31 & 22.6 & 34 & 53 & 2 & 3.8 \\
\hline Uveal melanoma & 43 & 78 & 12 & 15.4 & 0 & 0 & N/A & N/A \\
\hline Neuroendocrine & 5 & 9 & 6 & 67 & 14 & 23 & 0 & 0 \\
\hline Colorectal carcinoma & 14 & 22 & 9 & 40.9 & 8 & 11 & 1 & 9.1 \\
\hline Breast carcinoma & 3 & 7 & 1 & 14.3 & 3 & 4 & 0 & 0 \\
\hline Hepatocellular carcinoma & 5 & 7 & 1 & 14.3 & 0 & 0 & N/A & N/A \\
\hline Cholangio-carcinoma & 2 & 4 & 0 & 0 & 3 & 4 & 1 & 25 \\
\hline Other & 6 & 10 & 2 & 20 & 6 & 11 & 0 & 0 \\
\hline
\end{tabular}

$\mathrm{H}_{2} \mathrm{O}$, sterile water; $\mathrm{D}_{5} \mathrm{~W}, 5 \%$ dextrose in water; N/A, not applicable.

$\mathrm{D}_{5}$ W. A previous data set of 128 infusions using $\mathrm{H}_{2} \mathrm{O}$ was included as well (4). Patients in the comparison group were treated using an identical technique, as one of the current investigators (DBB) was involved with the previous study (4). Thus, 112 patients were treated as follows: 78 with $\mathrm{H}_{2} \mathrm{O}$ and 34 with $\mathrm{D}_{5} \mathrm{~W}$. Thirty-seven of the $78 \mathrm{H}_{2} \mathrm{O}$ patients and 14 of the $34 \mathrm{D}_{5} \mathrm{~W}$ patients were male.

Patients were scheduled for treatment after clinic assessment, including review of relevant cross-sectional imaging (computed tomography and/or magnetic resonance imaging). Mapping arteriography was performed as described previously (1). Criteria for treatment with Y90 microspheres included: i) Confirmed unresectable liver-dominant disease; ii) an East Coast Oncology Group performance status of 0-2; and iii) adequate liver function (bilirubin of $<1.8 \mathrm{mg} / \mathrm{dl}$ ).

Patients were excluded from treatment if there was: i) A life expectancy of $<3$ months, ii) side branch flow to the gastrointestinal tract that could not be avoided or embolized, and iii) the estimated lung dose was expected to exceed 25 Gray.

Y90 treatment. Y90 infusion was performed 7-10 days after mapping. The dose was prescribed using the body surface area (BSA) method and calculated as: A Gigabecquerel $(\mathrm{GBq})=(\mathrm{BSA}-0.2)+\mathrm{V}_{\text {tumor }} / \mathrm{V}_{\text {liver }}$, where $\mathrm{A}$ represents prescribed activity in $\mathrm{GBq}$ and $\mathrm{V}_{\text {tumor }}$ and $\mathrm{V}_{\text {liver }}$ represent the volume of the tumor and total infused liver volume, respectively. BSA in square meters was calculated as: $0.20247 \mathrm{x}$ height in $\mathrm{m}^{0.725} \mathrm{x}$ weight in $\mathrm{kg}^{0.425}$.

Patients were treated with lobar therapy. In the setting of bilobar disease, sequential infusions were performed 5-6 weeks apart.

A standard infusion protocol was followed for all resin microsphere infusions. These infusions were performed off label as non-colorectal metastases were treated. For the patients with colorectal cancer metastases, infusions were off label as intra-arterial chemotherapy was not used. Two interventional radiologists with 5 and 19 years experience performed the infusions (AJL, DBB). No anti-reflux devices or occlusion balloon techniques were used. The proprietary delivery kit was used in all the cases with the microspheres pushed into the delivery tubing with small aliquots of $\mathrm{H}_{2} \mathrm{O}$ or
$\mathrm{D}_{5} \mathrm{~W}$. After the line was cleared, 2-3 $\mathrm{ml}$ of non-ionic contrast (Optiray 350-Ioversol 74\%, Mallinckrodt Pharmaceuticals, Dublin, Ireland) was injected to evaluate for stasis. The process was repeated until the delivery vial was clear to vision. At this point, the vial was emptied by filling the priming line with air.

Stasis. Stasis was defined as a lack of antegrade arterial flow leading to procedure cessation prior to delivering the final air purge of the vial. Post-infusion assessment of residual activity was measured using a Ludlum Model 3 Survey Meter (Ludlum Measurements, Inc., Sweetwater, TX, USA).

Statistical analysis. The primary outcome variable was the incidence of stasis. The stasis incidents between $\mathrm{H}_{2} \mathrm{O}$ and $\mathrm{D}_{5} \mathrm{~W}$ cases were compared using a z-test, with $\alpha=0.05$. Secondary measures included differences in prescribed activity and the percentage of prescribed activity that was delivered between the $\mathrm{H}_{2} \mathrm{O}$ and $\mathrm{D}_{5} \mathrm{~W}$ groups. The secondary variables were evaluated using t-tests.

\section{Results}

A total of 112 patients were treated: 78 with $\mathrm{H}_{2} \mathrm{O}$ and 34 with $\mathrm{D}_{5} \mathrm{~W}$. Thirty-seven of the $78 \mathrm{H}_{2} \mathrm{O}$ patients and 14 of the $34 \mathrm{D}_{5} \mathrm{~W}$ patients were male. The group underwent 190 infusions: 137 were performed with $\mathrm{H}_{2} \mathrm{O}$ and 53 with $\mathrm{D}_{5} \mathrm{~W}$. Infusions and stasis events broken down by tumor type are shown in Table I. Thirty-one of the $137(23 \%) \mathrm{H}_{2} \mathrm{O}$ infusions developed stasis compared to 2 of the 53 infusions (4\%) with $\mathrm{D}_{5} \mathrm{~W}(\mathrm{z}=3.1, \mathrm{p}=1.1 \mathrm{E}-3)$ (Fig. 1). The $\mathrm{H}_{2} \mathrm{O}$ group had a significantly lower prescribed dose than that of the $\mathrm{D}_{5} \mathrm{~W}$ cohort $[0.75$ vs 1.04 millicuries (mCi), respectively; $\mathrm{t}=5.0, \mathrm{p}=1.1 \mathrm{E}-6]$ as demonstrated in Fig. 2A. Finally, the $\mathrm{H}_{2} \mathrm{O}$ group had a significantly lower percentage delivery of the prescribed dose compared to $\mathrm{D}_{5} \mathrm{~W}$, as seen in Fig. $2 \mathrm{~B}$ (92.7 vs. 101.5\%, respectively; $\mathrm{t}=3.8, \mathrm{p}=2.2 \mathrm{E}-4$ ). Over $97 \%$ of completed infusions with $\mathrm{H}_{2} \mathrm{O}$ and $\mathrm{D}_{5} \mathrm{~W}$ achieved $>90 \%$ delivery of prescribed activity while none of the infusions with early stasis reached $90 \%$ delivery (Table II). No patients in either group developed gastrointestinal signs/symptoms of ulceration. 
Table II. Percent delivery of resin Y90 with and without early stasis.

\begin{tabular}{lcc}
\hline Delivery percentage (\%) & Early stasis (\%) & No stasis (\%) \\
\hline$<50$ & $12 / 33(36)$ & $0 / 157(0)$ \\
$50-75$ & $10 / 33(30)$ & $0 / 157(0)$ \\
$76-90$ & $11 / 33(33)$ & $4 / 157(3)$ \\
$90-100$ & $0 / 33(0)$ & $153 / 157(97)$ \\
\hline
\end{tabular}

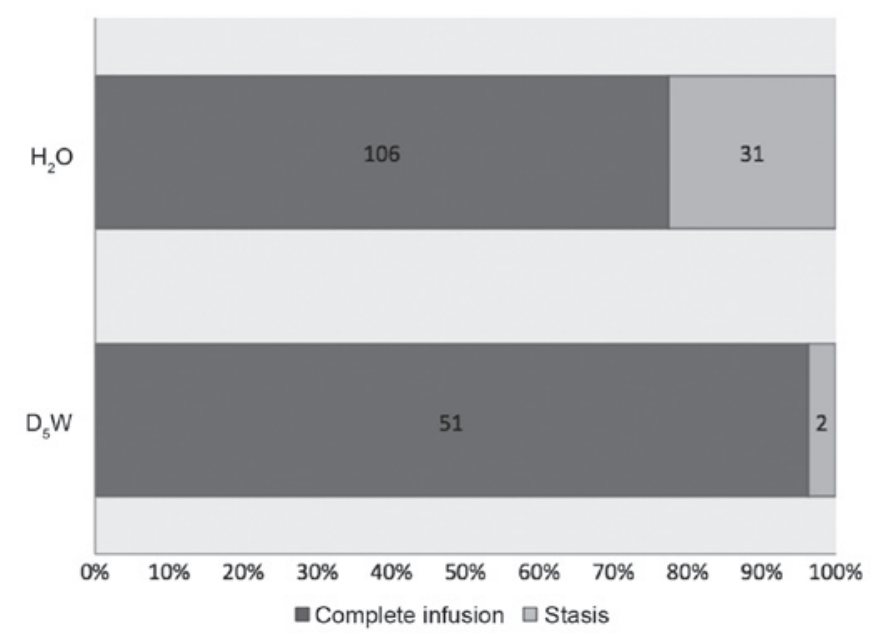

Figure 1. Percentage of infusions resulting in stasis for $\mathrm{H}_{2} \mathrm{O}(23 \%)$ vs. $\mathrm{D}_{5} \mathrm{~W}$ $(4 \%)$. This difference was statistically significant $(\mathrm{p}=1.1 \mathrm{E}-3)$.

\section{Discussion}

Delivery of resin $\mathrm{Y} 90$ microspheres with $\mathrm{D}_{5} \mathrm{~W}$ rather than $\mathrm{H}_{2} \mathrm{O}$ significantly reduces the rates of early arterial stasis. Improved delivery was achieved despite the $\mathrm{D}_{5} \mathrm{~W}$ group being prescribed significantly greater activity, which could have actually increased the risk of stasis. We also achieved more complete delivery of resin $\mathrm{Y} 90$ microspheres with $\mathrm{D}_{5} \mathrm{~W}$ compared to $\mathrm{H}_{2} \mathrm{O}$. In all the stasis events using either $\mathrm{D}_{5} \mathrm{~W}$ or $\mathrm{H}_{2} \mathrm{O}$, administered activity was $\geq 10 \%$ less than the prescribed activity. Although both glass and resin microsphere have been used to palliate patients with common metastatic tumors such as colorectal and breast cancer, the efficacy of glass microspheres was significantly decreased with the increasing tumor burden $(5,8,9)$. The number of microspheres in a $3 \mathrm{GBq}$ resin vial can be $\leq 80$-fold greater than the same activity of glass spheres based on the time from calibration (1). Potentially, resin Y90 can better saturate larger tumors and improve outcomes given the greater number of microspheres with preferential clustering in the viable, hypervascular portion of target masses (10). However, the theoretical benefit of more complete tumor coverage has been incompletely realized as incomplete delivery of the prescribed activity potentially decreases efficacy or the result in earlier time to progression.

Although there is a known $21 \%$ incidence of early stasis with $\mathrm{H}_{2} \mathrm{O}$, the etiology remains largely unexplained (4). In vivo use of $\mathrm{H}_{2} \mathrm{O}$ can result in intravascular hemolysis (11). The Food and Drug Administration reported 10 hemolysis cases in
A

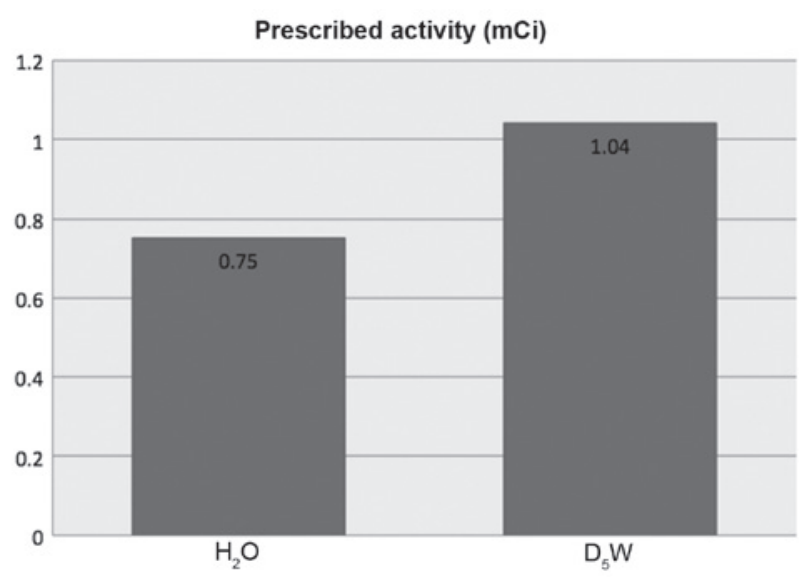

B

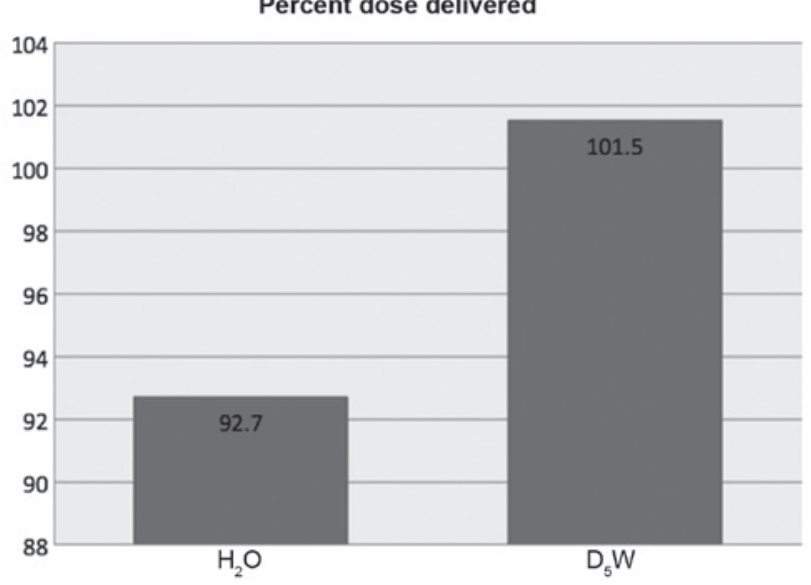

Figure 2. (A) The amount prescribed for $\mathrm{D}_{5} \mathrm{~W}$ cases $(1.04 \mathrm{GBq})$ was significantly higher than that for $\mathrm{H}_{2} \mathrm{O}(0.75 \mathrm{GBq}, \mathrm{p}=1.1 \mathrm{E}-6)$. (B) The mean percentage of the prescribed activity that was infused was significantly higher for $\mathrm{D}_{5} \mathrm{~W}(101.5 \%)$ than for $\mathrm{H}_{2} \mathrm{O}(92.7 \%$, $\mathrm{p}=2.2 \mathrm{E}-4)$. GBq, Gigabecquerel.

1999, following dilution of $25 \%$ albumin to $5 \%$ using $\mathrm{H}_{2} \mathrm{O}$ for plasmapheresis (11). The hypotonicity of the resulting infusion resulted in acute renal failure in five patients and death in one patient. Red blood cells lyse in hypotonic solutions such as those created with $\mathrm{H}_{2} \mathrm{O}$ (12). The release of intracellular contents following hemolysis expends endothelial nitric oxide, which increases the vasomotor tone (13-15). The end result of these events could include increased vascular spasm resulting in early stasis or in situ thrombosis, which is seen in other entities associated with hemolysis such as paroxysmal nocturnal hemoglobinuria or esophageal dysmotility $(16,17)$.

Previous research evaluated other potential risk factors contributing to early arterial stasis without finding a significant correlation (4). Considerations included relative tumor vascularity at cross-sectional imaging and previous intra-arterial therapy. However, neither of these factors affected stasis rates. Notably, the main limiting factor in the majority of stasis events with resin microspheres is use of $\mathrm{H}_{2} \mathrm{O}$. Tumors that appear hypovascular on computed tomography or magnetic resonance imaging are frequently hypervascular at angiography (18). We also perform chemoembolization using techniques associated with maximal long-term arterial patency (19). The findings of Chao et al, support the limitations of $\mathrm{H}_{2} \mathrm{O}$ (20). They described a reduction in early stasis from $15 \%$ with $\mathrm{H}_{2} \mathrm{O}$ to $4.5 \%$ with dilute contrast [Chao et al (20) presented at the 2014 Society 
of Interventional Radiology Annual Scientific Meeting]. Direct comparisons of $\mathrm{D}_{5} \mathrm{~W}$ and dilute contrast have not been reported. While dilute contrast allows real-time monitoring of vascular patency and possible reflux into non-target arteries, we did not have any gastrointestinal toxicities using $\mathrm{D}_{5} \mathrm{~W}$ with intermittent contrast injection in our group.

There are several important limitations to this study. First, our data are retrospective and include a variety of tumor types. However, as patients were treated consecutively with each delivery vehicle, the potential for selection bias is unlikely to have altered results in either direction. Furthermore, previous findings have has not shown any difference in stasis based on treatment/tumor history (4). Second, our sample size reflects that of a single approach to prescribing and infusing resin Y90. A multi-center study is necessary to substantiate these findings. Finally, the impact of early stasis on efficacy remains uncertain, and should be explored in future studies.

In summary, $\mathrm{D}_{5} \mathrm{~W}$ performs superiorly to $\mathrm{H}_{2} \mathrm{O}$ to deliver resin microspheres with lower rates of early arterial stasis and greater delivered activity. Future research may evaluate differences between $\mathrm{D}_{5} \mathrm{~W}$ and dilute contrast. Based on our findings, practitioners should eliminate use of $\mathrm{H}_{2} \mathrm{O}$ when performing resin microsphere infusion.

\section{Acknowledgements}

The authors would like to acknowledge Marni L. Gardner, DPh and Jeffrey A. Clanton, MS, DPh, BCNP for their assistance in dose preparation and patient care.

\section{References}

1. Lewandowski RJ, Sato KT, Atassi B, Ryu RK, Nemcek AA Jr, Kulik L, Geschwind JF, Murthy R, Rilling W, Liu D, et al: Radioembolization with $90 \mathrm{Y}$ microspheres: Angiographic and technical considerations. Cardiovase Intervent Radiol 30: 571-592, 2007.

2. Murthy R, Xiong H, Nunez R, Cohen AC, Barron B, Szklaruk J, Madoff DC, Gupta S, Wallace MJ, Ahrar K, et al: Yttrium 90 resin microspheres for the treatment of unresectable colorectal hepatic metastases after failure of multiple chemotherapy regimens: Preliminary results. J Vasc Interv Radiol 16: 937-945, 2005.

3. Stuart JE, Tan B, Myerson RJ, Garcia-Ramirez J, Goddu SM, Pilgram TK and Brown DB: Salvage radioembolization of liver-dominant metastases with a resin-based microsphere: Initial outcomes. J Vasc Interv Radiol 19: 1427-1433, 2008.

4. Piana PM, Bar V, Doyle L, Anne R, Sato T, Eschelman DJ, McCann JW, Gonsalves CF and Brown DB: Early arterial stasis during resin-based yttrium-90 radioembolization: Incidence and preliminary outcomes. HPB Oxf 16: 336-341, 2014.

5. Saxena A, Meteling B, Kapoor J, Golani S, Morris DL and Bester L: Is yttrium-90 radioembolization a viable treatment option for unresectable, chemorefractory colorectal cancer liver metastases? A large single-center experience of 302 patients. Ann Surg Oncol 22: 794-802, 2015.
6. van Hazel GA, Heinemann V, Sharma NK, Findlay MP, Ricke J, Peeters M, Perez D, Robinson BA, Strickland AH, Ferguson T, et al: SIRFLOX: Randomized phase III trial comparing first-line mFOLFOX6 (plus or minus bevacizumab) versus mFOLFOX6 (plus or minus bevacizumab) plus selective internal radiation therapy in patients with metastatic colorectal cancer. J Clin Oncol 34: 1723-1731, 2016.

7. Food and Drug Administration: Available at: http:// www.fda.gov/MedicalDevices/ProductsandMedicalProcedures/ DeviceApprovalsandClearances/PMAApprovals/ucm431264. htm. Accessed on June 15, 2016.

8. Gordon AC, Gradishar WJ, Kaklamani VG, Thuluvath AJ, Ryu RK, Sato KT, Gates VL, Salem R and Lewandowski RJ: Yttrium-90 radioembolization stops progression of targeted breast cancer liver metastases after failed chemotherapy. J Vasc Interv Radiol 25: 1523-1532, 1532, 2014.

9. Lewandowski RJ, Memon K, Mulcahy MF, Hickey R, Marshall K, Williams M, Salzig K, Gates VL, Atassi B, Vouche M, et al: Twelve-year experience of radioembolization for colorectal hepatic metastases in 214 patients: Survival by era and chemotherapy. Eur J Nucl Med Mol Imaging 41: 1861-1869, 2014.

10. Kennedy AS, Nutting C, Coldwell D, Gaiser J and Drachenberg C: Pathologic response and microdosimetry of (90)Y microspheres in man: Review of four explanted whole livers. Int J Radiat Oncol Biol Phys 60: 1552-1563, 2004.

11. Pierce LR, Gaines A, Finlayson JS, Varricchio F and Epstein JS: Hemolysis and acute renal failure due to the administration of albumin diluted in sterile water. Transfusion 39: 110-111, 1999.

12. Ramaswamykanive $\mathrm{H}$ and Greaves $\mathrm{J}$ : Intravenous infusion of sterile water for the treatment of hypernatraemia. Anaesth Intensive Care 42: 258-262, 2014.

13. Liao JC, Hein TW, Vaughn MW, Huang KT and Kuo L: Intravascular flow decreases erythrocyte consumption of nitric oxide. Proc Natl Acad Sci USA 96: 8757-8761, 1999.

14. Vaughn MW, Huang KT, Kuo L and Liao JC: Erythrocytes possess an intrinsic barrier to nitric oxide consumption. J Biol Chem 275: 2342-2348, 2000.

15. Rother RP, Bell L, Hillmen P and Gladwin MT: The clinical sequelae of intravascular hemolysis and extracellular plasma hemoglobin: A novel mechanism of human disease. JAMA 293: 1653-1662, 2005

16. Clark DA, Butler SA, Braren V, Hartmann RC and Jenkins DE Jr: The kidneys in paroxysmal nocturnal hemoglobinuria. Blood 57: 83-89, 1981.

17. Hirsch DP, Holloway RH, Tytgat GN and Boeckxstaens GE: Involvement of nitric oxide in human transient lower esophageal sphincter relaxations and esophageal primary peristalsis. Gastroenterology 115: 1374-1380, 1998 .

18. Sato KT, Omary RA, Takehana C, Ibrahim S, Lewandowski RJ, Ryu RK and Salem R: The role of tumor vascularity in predicting survival after yttrium-90 radioembolization for liver metastases. J Vasc Interv Radiol 20: 1564-1569, 2009.

19. Geschwind JF, Ramsey DE, Cleffken B, van der Wal BC, Kobeiter H, Juluru K, Hartnell GG and Choti MA: Transcatheter arterial chemoembolization of liver tumors: Effects of embolization protocol on injectable volume of chemotherapy and subsequent arterial patency. Cardiovasc Intervent Radiol 26: 111-117, 2003.

20. Chao C, Dagli M, Mondschein J, Stavropoulos W, Sudheendra D, Nadolski G, et al: Effect of substituting $50 \%$ issue for sterile water as the delivery medium for SIR-SPHERES: Improved dose delivery and decreased incidence of stasis. J Vasc Interv Radiol 2: S89, 2014. 